\title{
Hak Waris Anak Dalam Kandungan Menurut Fikih Syafi'i Dan Kompilasi Hukum Islam
}

\author{
Salman Alfarisi \\ Universitas Muhammadyah Sumatera Utara \\ alamatsurat2020@gmail.com
}

\begin{abstract}
Abstrak
Kompilasi Hukum Islam tidak mengatur hak waris anak dalam kandungan, sedangkan dalam literatur fikih klasik anak dalam kandungan merupakan ahli waris yang sah dan berhak mendapatkan bagian. Terjadinya kasus seorang meninggal dunia dan meninggalkan istri yang sedang hamil, kemudian kerabat suami meminta penetapan ahli waris di Pengadilan Agama, maka hal ini memicu kekosongan hukum karena belum adanya aturan yang terdapat dalam Kompilasi Hukum Islam. Penelitian ini bertujuan untuk mengetahui hak waris anak dalam kandungan dan bagiannya serta perbandingan dan prospek ke masa depan sehingga tidak terjadi kekosongan hukum. Metode penelitian yang digunakan penulis adalah penelitian yuridis normatif dengan pendekatan Conseptual Approach. Pendekatan ini beranjak dari pandangan-pandangan serta doktrin-doktrin yang berkembang di dalam ilmu hukum. Hasil penelitian ini menunjukkan bahwa di dalam Fikih Syafi'i anak dalam kandungan merupakan ahli waris dari orang tuanya dan kedudukannya sama dengan anak yang sudah lahir. Kompilasi Hukum Islam tidak mengatur hak waris anak dalam kandungan. Perbandingan hak waris anak dalam kandungan menurut Fikih Syafi'i dan Kompilasi Hukum Islam terletak pada pandangan hidupnya janin di dalam kandungan. Fikih Syafi'i memandang hidup terhadap janin dalam kandungan jika ada tanda-tanda kehidupan seperti gerak, sehingga janin tersebut berhak mendapat bagian. Kompilasi Hukum Islam memandang janin dalam kandungan tidak hidup sehingga janin tersebut tidak berhak menjadi ahli waris dan tidak berhak mendapat bagian. Untuk itu pemerintah harus tanggap dengan masalah kekosongan hukum mengenai kedudukan hak waris anak dalam kandungan dengan membuat peraturan mengenai hal kewarisan anak dalam kandungan yang dituangkan ke dalam Kompilasi Hukum Islam sebagai pedoman yang dipakai untuk menyelesaikan perkara di Pengadilan Agama..
\end{abstract}

Keyword : Waris, Anak, Dalam Kandungan, Fikih Syafi'i, Kompilasi Hukum Islam.

\section{PENDAHULUAN}


Kedudukan anak dalam kandungan di Indonesia tidak dijumpai aturan hukumnya dengan jelas. Dalam KHI pasal 174 yang mengatur kelompok-kelompok ahli waris terdiri dari (1) menurut hubungan darah: golongan laki-laki terdiri dari: ayah, anak laki-laki, saudara laki-laki, paman dan kakek. Golongan perempuan terdiri dari: ibu, anak perempuan, saudara perempuan dari nenek. Selanjutnya poin (2) menurut hubungan perkawinan terdiri dari duda atau janda. Kata anak laki-laki dan anak perempuan tidak dirinci dengan jelas apakah anak yang dimaksud sudah lahir atau masih dalam kandungan. Hingga pada penjelasan pasal pun tidak dijumpai penjelasan yang pasti sehingga dalam kasus anak dalam kandungan terdapat ketidak pastian.

Persoalannya adalah apabila seorang istri yang sedang hamil ditinggal mati oleh suaminya apakah bagian warisnya sesuai dengan furud al-Muqaddarah yaitu 1/4 karena tidak ada anak atau 1/8 karena ada anak dalam kandungan. Hal ini tentunya menimbulkan masalah dalam kepastian hukum dan tidak sebuah kemustahilan kasus seperti ini akan dihadapi oleh pengadilan agama.

\section{LANDASAN TEORI}

Proses waris memiliki hikmah yang cukup penting bagi kehidupan muslim, antara lain sebagai sarana prevensi kesengsaraan atau kemiskinan ahli waris. Apalagi kalau diingat bahwa sistem waris Islam memberi bagian sebanyak mungkin ahli waris dan kerabat. Bukan saja anak-anak pewaris, tetapi juga orang tua, suami dan isteri, saudarasaudara bahkan cucu, kakek atau nenek. Bahkan dalam proses pembagian hartapun diajarkan agar ahli waris memberi atau menyedekahkan bagi orang-orang miskin dan yatim yang hadir khususnya di antara kerabat (QS. anNisa': 8), serta menyedekahkan harta peninggalan melalui institusi wasiat, baik kepada kerabat seperti ibu bapak dan di luar kerabat juga kepada isteri untuk menjaga kesejahteraannya (QS. al-Baqarah: 180 dan 240).

Islam menganjurkan setiap muslim berwasiat dan memberikan sebagian harta peninggalan kepada orang miskin. Hal ini mengisyaratkan bahwa Islam menghendaki harta kekayaan itu berputar bukan saja di antara kerabat tetapi juga di antara muslim dan bahkan di antara masyarakat umum. Berbeda dengan sistem kapitalis misalnya, di mana individu mempunyai hak menguasai harta kekayaan, tanpa adanya aturan moral yang membatasi pertimbangan kemasyarakatan dalam upaya menyalurkan dan mendayagunakan kekayaan.

Sistem demikian mengakibatkan terjadi dua kutub yang saling berhadapan. Satu pihak orang-orang miskin semakin terlantar karena tidak ada tumpuan atau institusi sebagai tempat bergantung, di pihak lain terjadi penimbunan atau monopoli dari orang-orang yang memiliki harta kekayaan. Keyakinan Islam nilai usaha sangat ditekankan karena Allah akan memberi rezeki sesuai dengan yang diupayakan manusia (QS. anNajm: 39). 
Anak dalam kandungan merupakan ahli waris yang sah bagi orang tuanya. Hal ini didasarkan pada hadis Rasul:

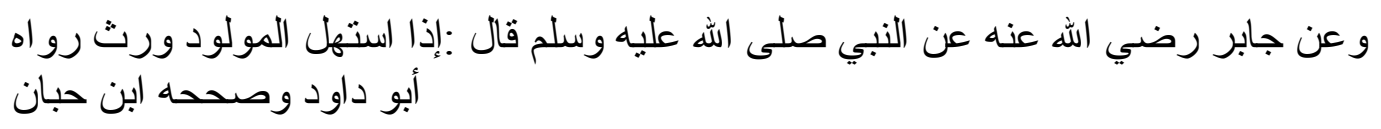

Artinya: dari Jabir r.a nabi SAW bersabda: apabila telah berteriak (bersuara) anak yang dilahirkan maka ia adalah ahli waris. (HR. Abu Daud dan disahihkan oleh Ibnu Hibban).

\section{METHOD}

Penelitian ini merupakan peneltian normatif. Penelitian normatif yuridis merupakan penelitian yang difokuskan dalam mengkaji kaidahkaidah atau normanorma dalam hukum positif. Dilihat dari jenis penelitian maka penelitian ini merupakan penelitian kepustakaan (library research). Pendekatan yang digunakan adalah pendekatan konseptual (Conseptual Approach).

Analisis teologis terhadap dasar hukum kewarisan Islam, dalam Al- Qur'an tak ada satupun ayat yang membahas porsi bagian kewarisan anak yang masih dalam kandungan, karena oleh sebab itu agar supaya kejelasan dan keamanan akan lebih baik jika anak yang ada dalam kandungan di tunggu kelahirannya untuk memastikan jenis kelaminnya, hidup, meninggalnya, agar haknya bisa jelas. Dan tidak menimbulkan masalah terhadap ahli waris yang lainya. Karena di dalam Kompilasi Hukum Islam tak ada satupun pasal yang mengatur terhadap bagian anak yang masih dalam kandungan. Padahal tidak akan menutup kemungkinan bahwa di kalangan masyarakat terjadi kasus dimana pewaris meninggal dunia dan istrinya sedang mengandung anak. Dengan demikian sangatlah penting tentang penetapan bagian anak dalam kandungan sebagai ahli waris yang mesti diatur dalam peraturan perundang-undangan di Indonesia.

\section{PEMBAHASAN}

Pemilihan Pancasila sebagai dasar negara yang tidak sekuler dan teokratis selanjutnya membawa implikasi terhadap paradigma pengembangan hukum Islam. Fikih yang mulanya dinamis dan fleksibel tiba-tiba perlu diregulasikan.Ini merupakan dampak dari proses akomodasi terhadap kekuatan politik Islam yang menghendaki tuntutan pelaksanaan atas hukum Islam. Karena itulah, wajah-wajah akomodatif itu hingga kini dapat terlihat dalam berbagai regulasi. Salah satunya adalah Kompilasi Hukum Islam yang disahkan melalui Instruksi Presiden No. 1 Tahun 1991.

Perlu dipahami, dalam hal memposisikan Kompilasi Hukum Islam dalam ruang discourse yang berkelindan dengan fenomena-fenomena di sekitarnya, bagaimanapun Kompilasi Hukum Islam merupakan langkah positivisasi hukum Islam karena disahkan oleh negara yang menganut aliran positivisme yuridis. Aliran ini berpendapat bahwa hukum dapat diterima setelah mendapatkan bentuk positifnya dari suatu instansi yang berwenang. Dalam perspektif inilah Marzuki Wahid dan Rumadi (2001) kemudian menjuluki fikih mazhab negara untuk Kompilasi Hukum Islam. 
Penyebutan itu didasari bahwa Kompilasi Hukum Islam merupakan fikih yang dalam proses inisiasi, perumusan dan pengesahan berada di tangan negara atau perpanjangan tangannya. Fikih yang secara terminologis berarti al-fahmu (pemahaman) masuk dalam ruang sensor negara sehingga nilai. benar atau tidaknya ditentukan oleh negara. Ruang imajinasi ini semakin dikukuhkan dengan anggapan Kompilasi Hukum Islam sebagai fikih Indonesia yang genesisnya dapat kita temukan dalam pemikiran Hasbi ash-Shiddieqy dan Hazairin. Merupakan usaha langkah positivisasi hukum Islam babak awal, wajar saja Kompilasi Hukum Islam tidak mengcover semua problematika hukum yang ada di masyarakat seperti hak dan kedudukan waris anak dalam kandungan, sehingga perlu dilakukan perubahan hukum mengingat begitu vitalnya posisi Kompilasi Hukum Islam bagi umat Islam di Indonesia. Dengan adanya perubahan atau re-formulasi Kompilasi Hukum Islam diharapkan dapat memberikan keadilan hukum dan jaminan hak dan kewajiban setiap individu.

Permasalahan dalam proses reformulasi Kompilasi Hukum Islam terbentur sejumlah kesulitan apalagi berkaitan dengan biaya dan waktu, maka Mahkamah Agung bisa mengeluarkan aturan khusus misalnya dalam bentuk surat edaran tentang bagian waris anak dalam kandungan, sehingga dengan adanya aturan tersebut bisa menjadi alas/dasar hukum bagi pengadilan di Indonesia dan lebih menjamin hak-hak waris anak dalam kandungan.

\section{KESIMPULAN}

Berikut kesimpulan yang dapat peneliti ambil sebagai jawaban dari rumusan masalah, yaitu:

1. Anak dalam kandungan merupakan ahli waris yang sah dari orang tuanya menurut Fikih Syafi'i, kedudukannya sama dengan anak yang sudah lahir. Pendapat mazhab Syafi'i dilandasi dengan QS Surat al-Ahqaf ayat 15 dan Surat al-Luqman ayat 14 serta Hadis sahih yang diriwayatkan oleh Imam Abu Daud dan Ibnu Hibban.

2. Kompilasi Hukum Islam tidak mengatur hak waris anak dalam kandungan, sehingga anak dalam kandungan tidak berhak mendapatkan bagian dari harta warisan.

3. Perbandingan hak waris anak dalam kandungan menurut fikih Syafi'i dan Kompilasi Hukum Islam terletak pada pandangan hidupnya janin di dalam kandungan. Fikih Syafi'i memandang hidup terhadap janin dalam kandungan jika ada tanda-tanda kehidupan seperti gerak, sehingga janin tersebut berhak menjadi ahli waris dan berhak mendapatkan bagian seperti anak yang sudah dilahirkan. Sedangkan Kompilasi Hukum Islam memandang bahwa janin dalam kandungan tidak hidup sehingga janin tersebut tidak berhak menjadi ahli waris dan tidak berhak mendapat bagian.

\section{DAFTAR PUSTAKA}


'Audah, Jaser. 2013Maqasid al-Shariah: A beginner's Guide, alih bahasa:

'Ali 'Abdelmon'im, Al-Maqasid Untuk Pemula, Yogyakarta: Suka Press,

Absori, 2009Perlindungan Hukum Hak-hak Anak dan Implementasinya diIndonesia Pada Era Otonomi Daerah, T.tp;

Abu Hamid, 1413. al-Mustasfa fi Ilm al-Ushul, ed. Mohammed Abdul Salam Abdul Shafivol. I Beirut: Dar al-Kutub al-Ilmiyyah,

Afdal, 2003, Penerapan Hukum Waris Islam Secara Adil, Airlangga University Press, Surabaya,

Afriqiy. Muhammad bin Makram bin Manzur al-. tth. Lisan al-Arab, Dar alShadr, Ali, Achmad. 2008. Menguak Realitas Hukum, Fajar Interpretama, Jakarta,

Ali, M. Daud. 1990, Asas Hukum Islam, Jakarta, Rajawali Press,

Dahlan, Abdul Azis, dkk. 1996., Jakarta: Ichtiar Baruvan Hoeve,

Daud, Abu. t.th. Sunan Abu Daud. Beirut: Dar Muassat al-Risalah,

Departemen Agama RI, 2002.Al-Quran dan Terjermahannya, Semarang: Toha Putra,

Dirdjosisworo, Soedjono. 1984. Filsafat Peradilan Pidana dan Perbandingan Hukum, Bandung: CV. Armico,

Direktorat Pembinaan Badan Peradilan Agama Islam, 2001.Himpunan Peraturan Perundang- Undangan Dalam Lingkungan Peradilan Agama, Jakarta: Direktorat Jenderal Pembinaan Kelembagaan Agama Islam Departemen Agama RI,

Djadzuli, A. 1997. Fikih Jinayat: Upaya Menanggulangi Kejahatan dalam Islam, Jakarta: PT. Raja Grafindo Persada,

Fafis, Hamzah Abu, 2003. Al-Mawaris Wa alwashaya fi Syari'ati Al-Islamiyah

Fiqhan wa 'amalan., Elga,

Fasi, Allal al- t.th.Maqashid asy-Syari'ah wa Makarimuha,Beirut: Dar al-Fikr,

Gultom, Maldin.2012. Perlindungan Hukum terhadap Anak dan Perempuan,

Refika Adhitama, Bandung,

Hamid, Muhammad Muhyidin Abdul. 2009.Panduan Waris Empat Mazhab,

Jakarta: Al-Kautsar,

Hanafy, Ibnu Nujaim al-, t.thal-Asybah wa al-Nazhair.Beirut: Dar al-Kutub al-

Ilmiyah,

Hazm,Ibnu. 1970.Al-Muhalla bil Atsar, Mesir, Mathba'ah al Jumhuriyyah,

Intruksi Presiden Nomor 1 tahun 1991 Tentang Kompilasi Hukum islam pasal 174 ,

Iriyanti. 2017. Bagian Waris anak dalam Kandungan, Jurnal. Jurnal Surya

Kencana Dua: Dinamika Masalah Hukum dan Keadilan Vol. 4 Nomor 2

Desember, Ishaq, Sulaiman Bin al-Asy'ast bin. t.thSunan Abi Daud. Beirut:

Maktabah al-Syari'ah,

J. Satrio. 1992. Hukum Waris, Alumni, Bandung,

Jurnal Insitusi Politeknik Ganesha Medan

Juripol, Volume 1 Nomor 1 Februari 2020 
Jalal, Abdul Rahman Yusuf.1969. al-Khulashah al- Wafiyah fi al-Mawaris alIslamiyah, Kairo: Dar al- Ta'lifi,

Kanang, Abdul Rahman. 2011.Perlindungan Hukum dan Pemenuhan Hak-hak KonstitusionalAnak,Makassar: Alauddin University Press,

Kansil, C.S.T. \& Christine S.T. 2003.Hukum Tata NegaraRepublik Indonesia 2, Rineka Cipta, Jakarta,

Komite Fakultas Syari'ah Al-Azhar. 2011. Hukum Waris, Jakarta: Senayan Abadi Publising,

Lubis, Zul Pahmi.2012. Nasab anak Zina Menurut Pendapat Mazhab

Syafi'i dan Hanafi, Skripsi Fakultas Syariah Institut Agama Islam Negeri,

Ma'lup, Louis.1973. al-Munjid Fi al-Lughah wa al- 'Alam, Bairut: al-

Syarghiyah,

Madkur, Muhammad salam.1999 al-Madkh li al-Fiqh al-Islami, Beirut: Dar al-

Fikr,

Mahmud, Akilah. 2012.Keluarga Sakinah, Makassar: Alauddin University Press,

Mamudji, Soerjono Soekanto dan Sri. 2002Penelitian Hukum Normatif, Jakarta:

Rajawali Press,

Maruzi, Muslih. 1997. Pokok-Pokok Ilmu Waris, Semarang: PT. Pustaka Rizki

Putra,

Marzuki, Peter Mahmud. 2005.Penelitian Hukum, Prenada Media, Jakarta,

Mulabari, Zainuddin bin Abdul Aziz al-.t.th.Terjemahan Fath al-Mu'in,

Toha Putra, Semarang,

Munawir, Ahmad Warsom al-. 1997. Kamus Almunawir Arab Indonesia

Terlengkap, Yogyakarta: Pustaka Progresif,

Mustari, Abdillah. 2002. Hukum Waris Perbandingan Hukum Islam dan Undang-

Undang Hukum Perdata Barat, Jakarta: Kencana,

Nawawi, Muhammad Bin Syarf an-.1991.al-Majmu' Syarh al-Muhazzab,

Beirut: Dar al-Fikr,

Obeidi, Hammad al-. 1401 H/ 1992 M al-Syatibi wa Maqasid al-Syariah,

Mansyurat Kuliat al-Da'wah al-Islamiyyah, Tripoli, cet. Pertama,

Qudamah, Ibnu. 1969. Al Mughni, Mesir: Mathba'ah al Qahirah,

Rafiq, Ahmad. 1995. Fiqh Mawaris, Jakarta: Raja Grafindo Persada,

Rahman, Abdul. 2011Perlindungan Hukum dan Pemenuhan hak konstitusional

Anak, Makassar: Alauddin University Press,

Rahman, Marwan A. 2018. Hakim Pengadilan Agama Medan.Wawancara

Pribadi.Pengadilan Agama Kelas I A Medan.

Rahman, Fatchur. 1981.Ilmu Waris. Bandung : PT al- Ma'arif,

Raysuni, Ahmad. 1992.Nadhariyyat al-Maqashid 'inda al-Imam asy-

Syatibiy, Beirut: al-Muassasah al-Jami'iyyah li ad-Dirasat wa anNasyr wa at-Tauzi,

Rofiq, Ahmad. 2012.Fiqh Mawaris, Jakarta: PT. Raja Grafindo Persada, 
Sabiq, Sayyid. 1988.Fiqih Sunnah, Jilid 14, Terj. Mudzakir A.S, Bandung:

Al-Ma'arif,

Salam, Izz ibn Abd al-. 1995. Maqasid al- Saum, ed. Iyad al- Tabba, 2nd,

Beirut: Dar al- Fikr,

Saleh, K. Wantjik. 1978.Hukum Perkawinan di Indonesia, Jakarta: Ghalia Indonesia,

Salman, Otje.2007.Kesadaran Hukum MasyarakatterhadapHukum Waris,

Cetakan Kedua, Alumni Bandung,

Shabuni, Muhammad Ali Ash-. 1995, al Mawaris Fisy Syari'atil Islamiyyah 'Ala

Dhani' al Kitab wa Sunnah. Terj. A.M. Basalamah "Pembagian Waris Menurut

Islam", Jakarta: Gema Insani Press,

Shidieqy, T.M. Hasbi Ash-. 1967.Fiqih Mawaris (Hukum-hukum Warisan dalam Syari'at Islam),Jakarta: Bulan Bintang,

Sunggono, Bambang.1994. Hukum Lingkungan \&

DinamikaKependudukan, Citra Aditya Bakti, Bandung,

Suparman, Eman. 2007.Hukum waris Indonesia. Bandung: PT Refika

Aditama, 